Kalpa Publications in Engineering
Volume 1, 2017, Pages 246-258
ICRISET2017. International Conference on Re-
search and Innovations in Science, Engineering
\&Technology. Selected Papers in Engineering

\title{
Correlating Tensile Strength \& Peak Temperatures for Magnesium Alloy AZ91 during Friction Stir Welding Using Varied Tool Geometries \& FEA Tool
}

\author{
K. D. Bhatt ${ }^{1}$, Nikul Patel ${ }^{2}$, Vishal Mehta ${ }^{3}$ \\ ${ }^{1}$ Production Engineering Department, BVM Engineering College, V. V. Nagar, India, \\ kdbhatt@,bvmengineering.ac.in \\ ${ }^{2}$ Mechanical Engineering Department, Ipcowala Institute of Engineering \& Technology, \\ Dharmaj, India, nikpatel25@yahoo.com \\ ${ }^{3}$ Mechanical Engineering Department, CSPIT, Changa, India, \\ vishalmehta.me@,charusat.ac.in
}

\begin{abstract}
Magnesium \& its alloys are flammable for conventional fusion welding process. This adverse effect can be eliminated by a non-fusion solid state welding process, established by The Welding Institute (TWI) in 1991, called friction stir welding (FSW). This is applied in this investigation for joining two plates together by using non-consumable tools (three pin profiles) between two abutting plates of magnesium alloy AZ91 having $6 \mathrm{~mm}$ thickness. FSW process joins the plates with certain advantages such as low distortion, no shielding gas required, fine recrystallized microstructure, no fumes liberated during the process, etc. In Friction stir welding, process parameters such as welding speed, tool rotation speed, tool dimensions and axial force play an important role during the process. In the present work, the $6 \mathrm{~mm}$ thick plates of the said alloy are welded at traverse speed of $28 \mathrm{~mm} / \mathrm{min}$ to $56 \mathrm{~mm} / \mathrm{min}$ with tool rotation speed ranging from $710 \mathrm{rpm}$ to $1400 \mathrm{rpm}$. Tensile strength testing \& simulation of peak temperatures has been carried out for establishing correlationship between best parameters from the selected ones with temperature profiles obtained by those parameters for giving optimum structure-property relationship using different pin profiles.
\end{abstract}




\section{Introduction}

From among wide varieties of welding processes used in fabrication industries, friction stir welding is one of the categories of solid state welding processes. Friction stir welding (FSW) was invented at The Welding Institute (TWI) of The United Kingdom in 1991 as a solid state (fusion less) joining technique [1]. Friction stir welding is an environmental friendly, energy efficient and versatile joining process used to join low melting point metals \& alloys. Due to the advantages such as low distortion, no shielding gas requirement, fine recrystallized microstructure, no fumes liberated during the process, etc. it is considered to be the most significant development in metal joining technology. As compared to conventional welding methods, FSW consumes considerably less energy, no consumables such as a protective gas or flux, and produces no harmful emissions (gases) during welding, thereby making the process environmentally friendly.

Further, any aluminium alloy can be joined without concern for compatibility of composition or solidification cracking issues associated with fusion welding since FSW does not involve the use of filler metal and there is no melting. Also, with no modification in the process, dissimilar aluminium alloys and composites can be joined with equal ease [2]. The process parameters such as tool rotational speed, tool traverse speed and axial force as well as tool dimensions play an important role in obtaining a specific temperature profile and subsequent viscosity distribution within the material being welded; the former controlling the mechanical properties and later the flow stresses within the material in turn [3].

The prime objective of the present work is to simulate peak temperatures and temperature distribution at and ahead of the FSW tools during the friction stir welding by changing tool geometries and correlating those peak temperatures with the obtained values of tensile strengths using a simulation software for AZ91 magnesium alloy which is widely used in applications requiring high strength-toweight ratio as in aerospace. The alloy AZ91 Mg-alloy, possessing good formability, corrosion resistance and good strength compared to aluminum alloys, is also used in engine blocks, paddle shifters, car bodies etc. Being difficult, the on-line measurement of temperature during friction stir welding of metals $\&$ alloys, the software based assistance can be obtained for the same to predict the property variations for getting good quality weld [4].

\section{Literature survey}

FSW has been applied for the joining of nonferrous materials such as aluminium, copper, dissimilar metals and their alloys possessing low melting point successfully. It has been also applied but to a lesser extent for magnesium alloys. Under rare earth metal category, aluminium and magnesium have been used for structural applications because of its strength to weight ratio (more compared to other metals) and many attractive properties in structural field. Magnesium and its alloy are the third-mostcommonly-used structural metal, followed by iron and aluminium. There are many magnesium alloys used for different applications, AZ91 is one of the magnesium alloys, which was used for investigating the effect of FSW parameters on tensile strength. S. Ramesh Babu et al. investigated the microstructural and mechanical properties of extruded AZ31B during FSW and found that good welded zone and defect free stir zone are obtained with tool rotation speed of $1000 \mathrm{rpm}$ with a tool shoulder diameter of $24 \mathrm{~mm}$, tool traversing speeds of $75 \mathrm{~mm} / \mathrm{min}$ and $105 \mathrm{~mm} / \mathrm{min}$ [5]. K Panneerselvam and Lenin K. found that at constant rotational speed and welding speed threaded tool pin profile produces less force but square pin profile produces defect free welds of polypropylene plates [6]. 
Extruded Mg-2.0Nd-0.3Zn-1.0Zr (wt.\%) alloy was used by F. Y. Zheng et al. for investigating the change in microstructure and mechanical properties of friction stir welded plates and they observed that by increasing the passes of welding, average grain size decreases firstly and then increases and also that the Vikers hardness of stir zone is higher than parent material but tensile strength of advancing side of stir zone is lower than parent material [7]. Chaitanya Sharma et al. analyzed the heterogeneity of microstructure and mechanical properties of friction stir welded joints of Al-Zn-Mg alloy (AA7039) and found that weld nugget grain size decreases from top to bottom (with optical and scanning electron microscopy); top layer of joint was the strongest while middle layer was the weakest [8]. Mohsen Bahrami, et al. investigated the influence of different pin geometries using threaded tapered, triangular, square, four-flute square, and four-flute cylindrical pins, for AA7075/SiC nano-composite on microstructure using optical microscopy (OM) and scanning electron microscopy (SEM), tensile strength on tensile test machine and concluded that the highest UTS was obtained with triangular pin tool. Macroscopic fracture observed for specimen welded by four-flute cylindrical pin tool which failed in stir zone and remaining other specimens fractured in base metal far outside the stir zone [9]. Emad Salari et al. observed influence of tool geometry and rotational speed on mechanical properties and defect formation for 5456 aluminum alloy sheets and observed that optimum microstructure and mechanical properties were obtained for the joints produced with the stepped conical threaded pin profile with rotational speed of $600 \mathrm{rpm}$ [10]. Investigation made by S. Ugender et al. showed that the joint fabricated using tapered cylindrical pin profile exhibited more temperature and superior tensile properties compared to the joints fabricated by straight cylindrical pin profile for friction stir welding of AA2014 Aluminium Alloy [2].

K. Elangovan et al. found out the influences of tool pin profiles and welding speed for AA2219 Aluminium alloy fabricated by the friction stir welding and observed that the square pin profiled tool produces mechanically sound and metallurgical defect free welds compared to other tool pin profiles [11]. Even with the difficulty of embedding the thermocouples in the stirred zone nearer to rotating pin [12-15], several attempts have been made to estimate the maximum temperature within this zone based on the microstructure of the weld zone. [16-18]. Vinayak Malik et al. investigated the effect of tool pin profiles with the help of finite element simulation and they analyzed the temperature effect on tool pin profile. They used circular pin, triangular pin, square pin, rectangular pin, pentagonal pin, hexagonal pin geometries of tool pin for investigating effect of temperature and finally concluded that square pin profile consume less power and defect diminishes for frustum type pins when compared to straight pins [19]. P H Shah and Dr. Vishvesh Badheka, investigated temperature distribution and joint properties of aluminium alloys and found that the temperatures on the advancing side of the weld are bit higher than that of the retreating side of the weld [20].

For aerospace application, Sahin Suenger, et al. analyzed the influence of the process temperature on hardness of AA2219 alloy. For this, they took 10 measurements at $1 \mathrm{~mm}$ distance apart from each other from the center; and from experimental investigation, they concluded that a high formability of the joint requires a low hardness increase at the welding seam. The results of this paper show that this can be achieved by a reduced rotational speed, an increased welding speed and reduced axial force [21]. B. Ratna Sunil, et al. joined two different magnesium alloys (AZ31 and AZ91) with the help of FSW and measured tensile strength, yield strength and elongation and concluded that FSW can be used as a potential technique to join dissimilar Mg alloys, particularly AZ series alloys, for various structural applications [22].

Friction stir welding process also used for joining dissimilar alloy and alloy having different characteristics. P. Rama Pinneswari et. al. joined two magnesium alloys with the help of FSW process using different variable process parameters and concluded that at $1400 \mathrm{rpm}$ tool rotating speed and 25 $\mathrm{mm} / \mathrm{min}$ feed rate, FSW can be used as a potential technique to join dissimilar Mg alloys, particularly AZ series alloys [23]. Ugender Singarapu et. al. investigated that the AZ31B magnesium alloy at tool 
rotating speed of 900 to $1400 \mathrm{rpm}$ and welding speed of 25 to $75 \mathrm{~mm} / \mathrm{min}$ can give defect free welded zone at micro level with different tool material like SS, HSS and H13. Also, they analyzed the effect of variable parameters based on results that rotational speed has the highest percentage of contribution on UTS and micro hardness, whereas welding speed has the lowest one on mechanical properties such as UTS, YS, \% EL, impact toughness and micro hardness values [24].

\section{Experimental work}

The plate of dimensions $100 \mathrm{~mm}$ x $150 \mathrm{~mm}$ x $6 \mathrm{~mm}$ of magnesium alloy AZ 91 having chemical composition of the alloy as per Table 1 [25] were selected for experimental work. The HCHCr D2 grade material was used for FSW tool with different tool pin geometries by setting hardness of tool ranging from 60 to $61 \mathrm{HRC}$.

\begin{tabular}{llllllll}
\hline$\% \mathrm{Al}$ & $\% \mathrm{Zn}$ & $\% \mathrm{Mn}$ & $\% \mathrm{Fe}$ & $\% \mathrm{Si}$ & $\% \mathrm{Cu}$ & $\% \mathrm{Ni}$ & $\% \mathrm{Mg}$ \\
\hline 9.2 & 0.32 & 0.84 & 0.003 & 0.12 & 0.03 & 0.01 & Balance \\
\hline
\end{tabular}

Table 1 Chemical Composition of AZ91 Magnesium Aloy

For performing experiments, FSW tool pin geometries were selected as: (1) Threaded straight cylindrical pin (TSCP), (2) Tapper cylindrical pin (TCP) and (3) Straight cylindrical pin (SCP).

Taguchi technique for design of experiment (DOE) has been implemented for finding number of experiments to be performed for selected variables such as tool pin geometry, welding speed, and tool rotation speed for FSW. This design models have been prepared by choosing three levels as shown in Table 2 [25]. Taguchi design was used for experimentation by applying L9 orthogonal array, taking three levels for each factor.

\begin{tabular}{lccccc}
\hline Sample & Control factor & Unit & Level 1 & Level 2 & Level 3 \\
\hline A & FSW Tool & & TSCP & TCP & SCP \\
\hline B & Rotational Speed (RS) & rpm & 710 & 1000 & 1400 \\
\hline C & Welding Speed (WS ) $\mathrm{mm} / \mathrm{min}$ & 28 & 40 & 56 \\
\hline
\end{tabular}

Table 2 FSW Parameters for DOE

Table 2 shows the tool, rotational speed and welding speed along with experiment number showing the order of experiment to be performed [25].

\begin{tabular}{cccc}
$\begin{array}{l}\text { Experiment } \\
\text { No. }\end{array}$ & Tool & $\begin{array}{l}\text { Rotational } \\
\text { Speed } \\
\text { (RS)(rpm) }\end{array}$ & $\begin{array}{l}\text { Welding } \\
\text { Speed (WS) } \\
\text { (mm/rev) }\end{array}$ \\
\hline $\mathbf{1}$ & TSCP & 710 & 28 \\
\hline $\mathbf{2}$ & TSCP & 1000 & 40 \\
\hline $\mathbf{3}$ & TSCP & 1400 & 56 \\
\hline $\mathbf{4}$ & TCP & 710 & 40 \\
\hline $\mathbf{5}$ & TCP & 1000 & 56 \\
\hline
\end{tabular}




\begin{tabular}{llcl}
\hline $\mathbf{6}$ & TCP & 1400 & 28 \\
\hline $\mathbf{7}$ & SCP & 710 & 56 \\
\hline $\mathbf{8}$ & SCP & 1000 & 28 \\
\hline $\mathbf{9}$ & SCP & 1400 & 40 \\
\hline & Table 3 FSW Parameters for Experiments
\end{tabular}

\section{Results and discussions}

Tensile testing was performed for knowing tensile strength of weld joint obtained by nine experiments (Table 4) [25].

\begin{tabular}{cc}
\hline Experiment No. & $\begin{array}{l}\text { Tensile Strength (TS) } \\
(\text { MPa) }\end{array}$ \\
\hline 1 & 76.1667 \\
\hline 2 & 57.4000 \\
\hline 3 & 23.5400 \\
\hline 4 & 58.2000 \\
\hline 5 & 11.1167 \\
\hline 6 & 1.1100 \\
\hline 7 & 8.9100 \\
\hline 8 & 26.83333 \\
\hline 9 & 22.3667 \\
\hline
\end{tabular}

After performing all experiments, observation made by observing the weld pool of friction stir welded plates under optical metallurgical microscope at 100X magnification, and all weld pools were found different. The variation in parameters has affected the welding which is clearly visible. Microscopic images were taken for observing the inside defect/s or crack/s in the weld pool by magnifying the cross-section of weld pool, perpendicular to the weld top surface. In experiment 1, as shown in Fig. 1, only inside defect (void) was observed but no defect or crack was present on the top surface or on back surface of the welded plates.

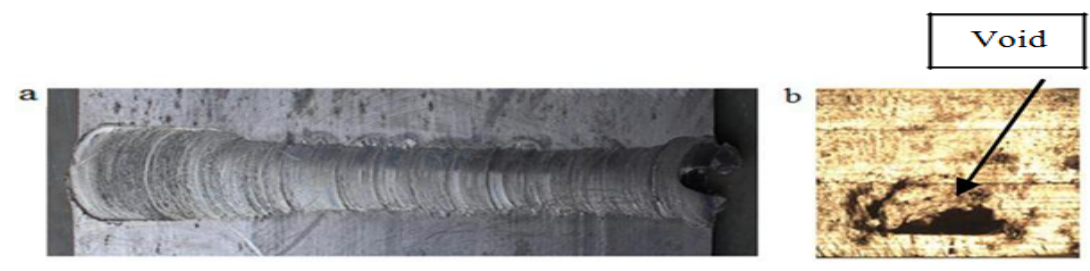

Fig. 1. Experiment 1(a) weld pool close view;(b) microscopic view (100X). 


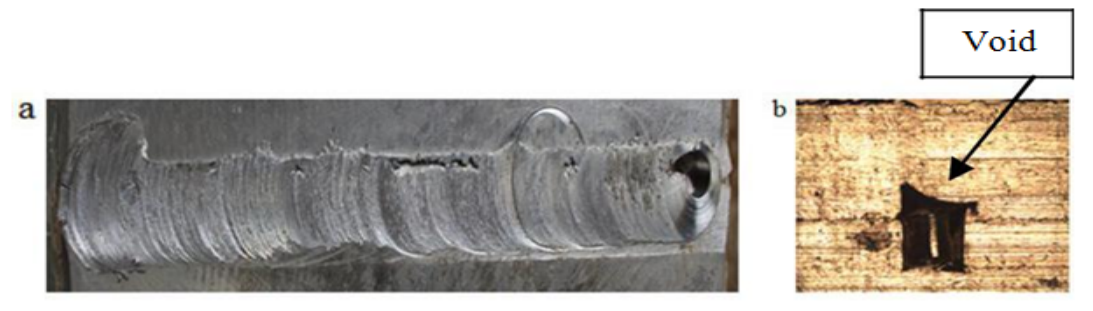

Fig. 2. Experiment4(a) weld pool close view;(b) microscopic view(100X)

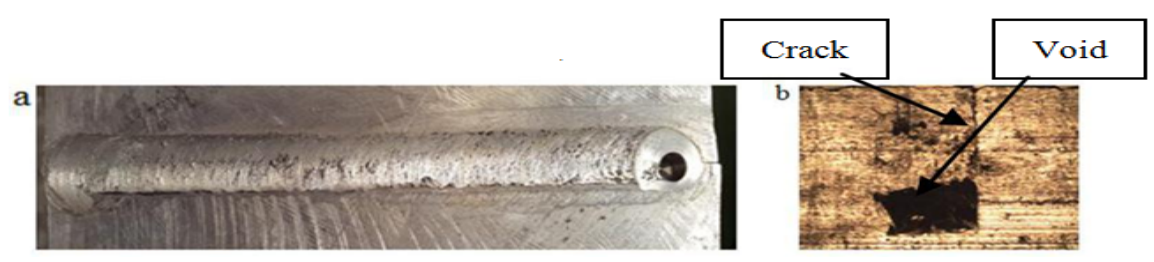

Fig. 3. Experiment 8(a) weld pool close view;(b) microscopic view (100X).

During experiment 2, defect (void) present inside the weld pool was observed and tool was broken at the middle of the length of the welding line due to increase in the speed of tool rotation. Tool got broken at near to just starting of the operation in experiment 3 and welding was not done; only the top surface joined slightly together but the full thickness of two plates was not welded that could be observed (un-welded portion) in microscopic view.

During experiment, 4, 5 and 6, no tool was damaged but the welding was not proper because of lack of heat generation due to tool geometry used (tapper cylindrical pin tool). Crack was detected in the top surface of the weld pool and defects such as voids were found inside of the weld pool as shown in Fig. 2. Experiment 7, 8 \& 9 were performed with straight cylindrical pin tool and the weld joint obtained by these experiments was having defects (crack and void) on the weld pool top surface as well as inside of the weld pool as shown in Fig. 3. The peak temperatures obtained by running the simulations for FSW of AZ91 plates in FEA software are shown in experimental as well as graphical forms in figures from 4(a) to 7(b) along with the strength values measured experimentally as indicated in Table 4. 


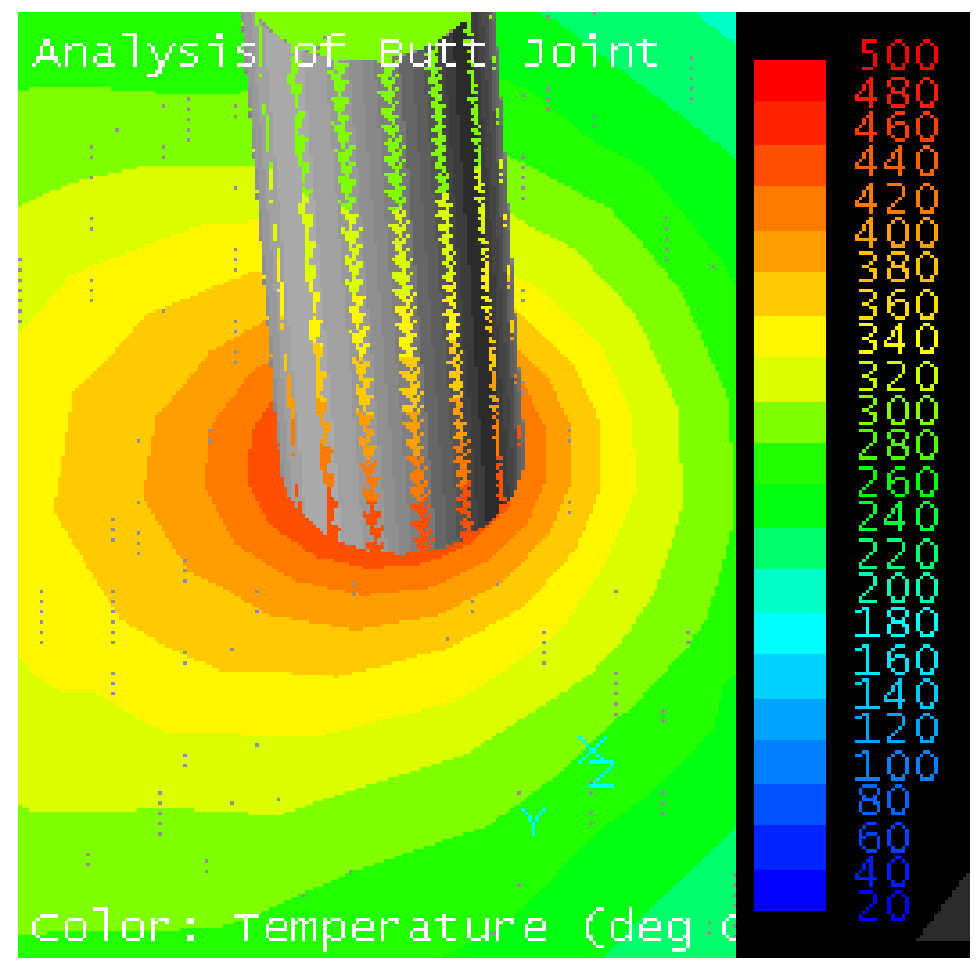

Figure 4a: $\mathrm{RS}=710 \mathrm{rpm}, \mathrm{WS}=28 \mathrm{~mm} / \mathrm{min},(\mathrm{Pin}=\mathrm{TSCP})$

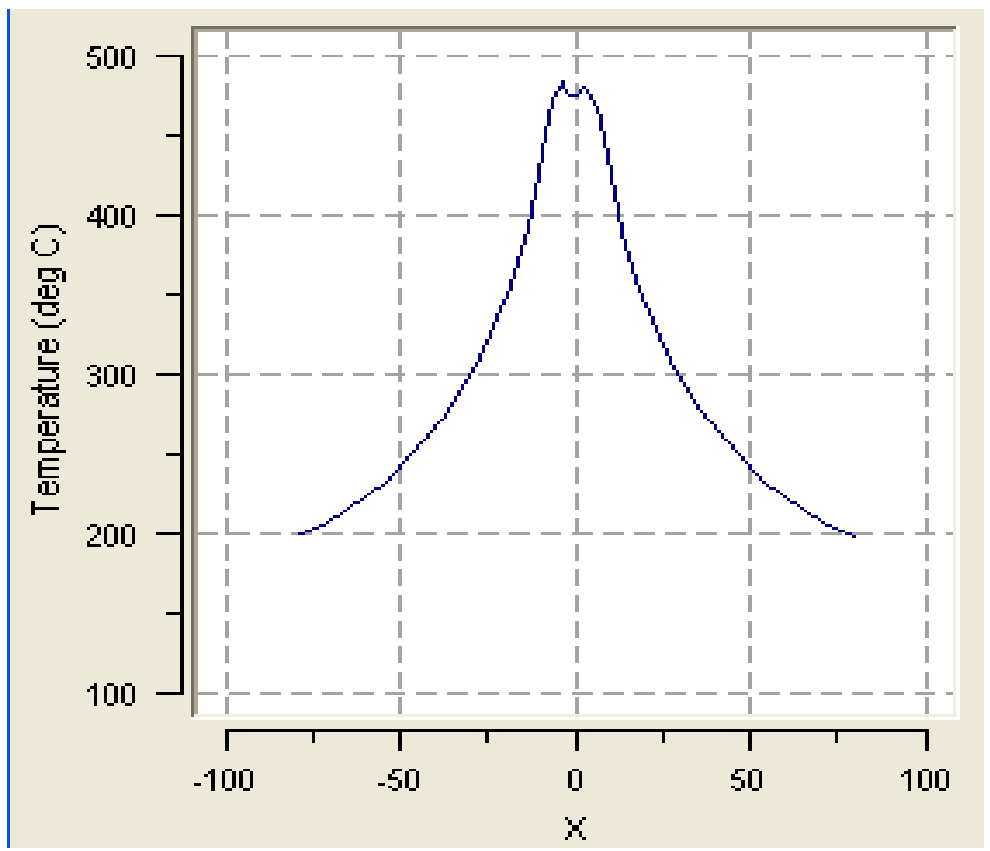

Figure 4b: RS $=710 \mathrm{rpm}, \mathrm{WS}=28 \mathrm{~mm} / \mathrm{min},(\mathrm{Pin}=\mathrm{TSCP})$ Max. Temp $=490 \mathrm{oC} ; \mathrm{TS}=76.17 \mathrm{MPa}$ 


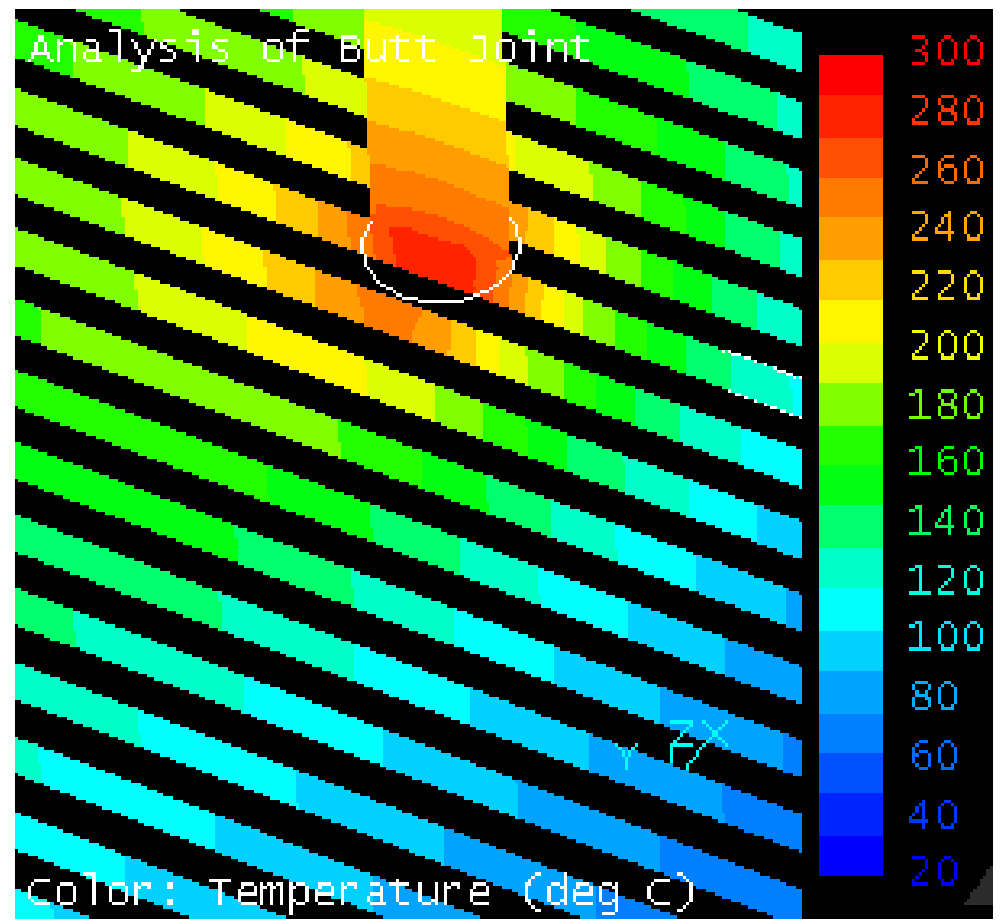

Figure 5a: $\mathrm{RS}=1000 \mathrm{rpm}, \mathrm{WS}=56 \mathrm{~mm} / \mathrm{min},(\mathrm{Pin}=\mathrm{TCP})$

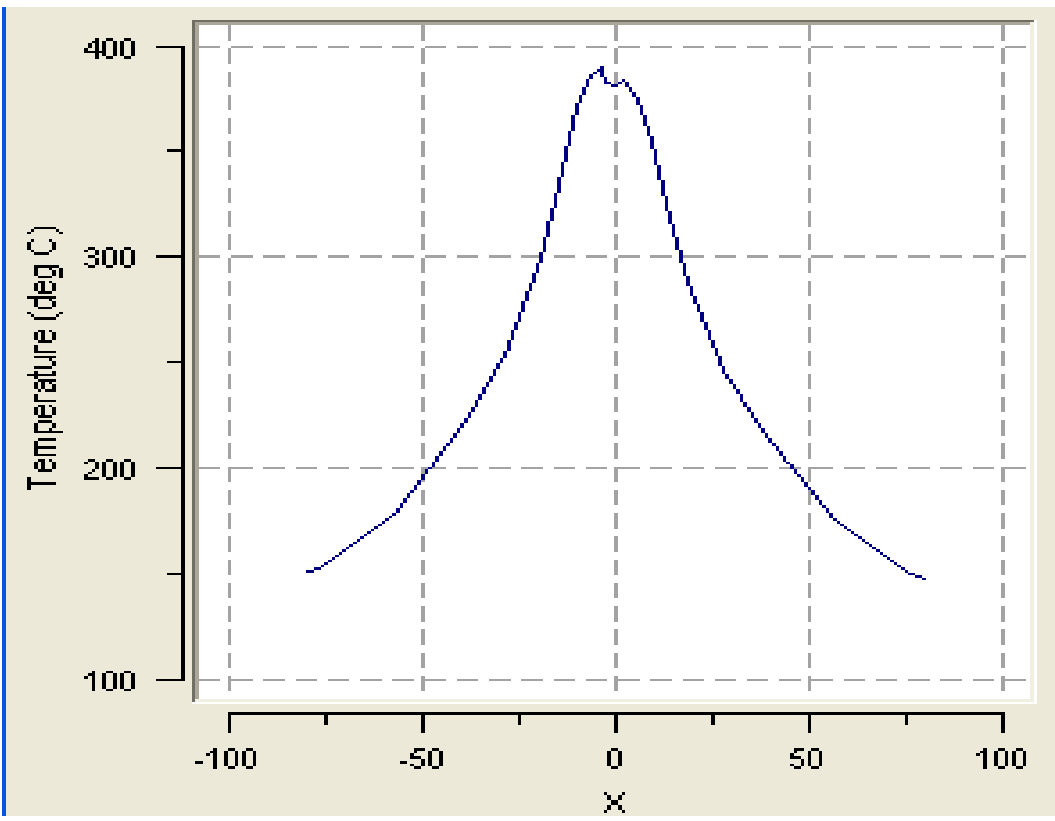

Figure 5b: RS $=1000 \mathrm{rpm}, \mathrm{WS}=56 \mathrm{~mm} / \mathrm{min},(\mathrm{Pin}=\mathrm{TCP})$ Max. Temp $=393 \mathrm{oC} ; \mathrm{TS}=11.17 \mathrm{MPa}$ 


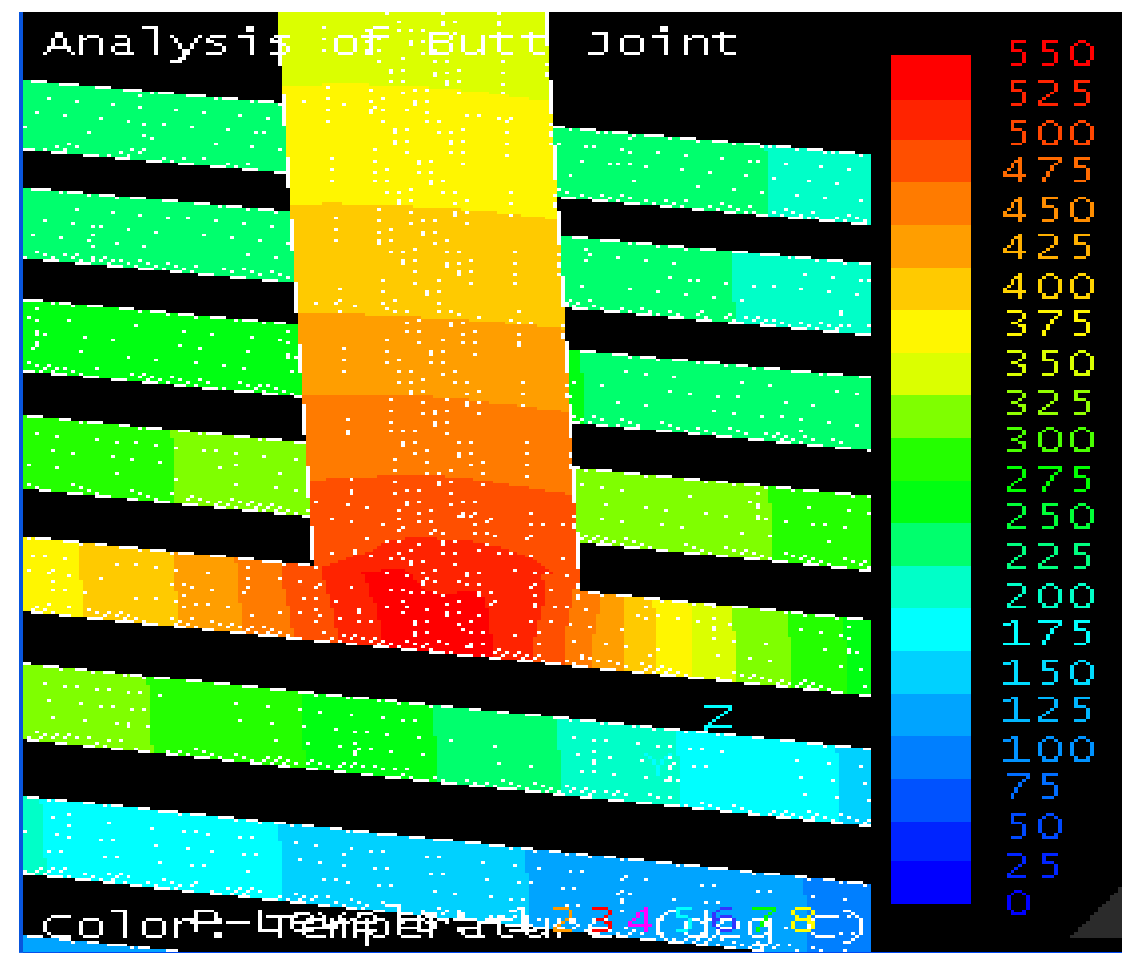

Figure 6a: RS $=1000 \mathrm{rpm}, \mathrm{WS}=40 \mathrm{~mm} / \mathrm{min},(\mathrm{Pin}=\mathrm{TSCP})$

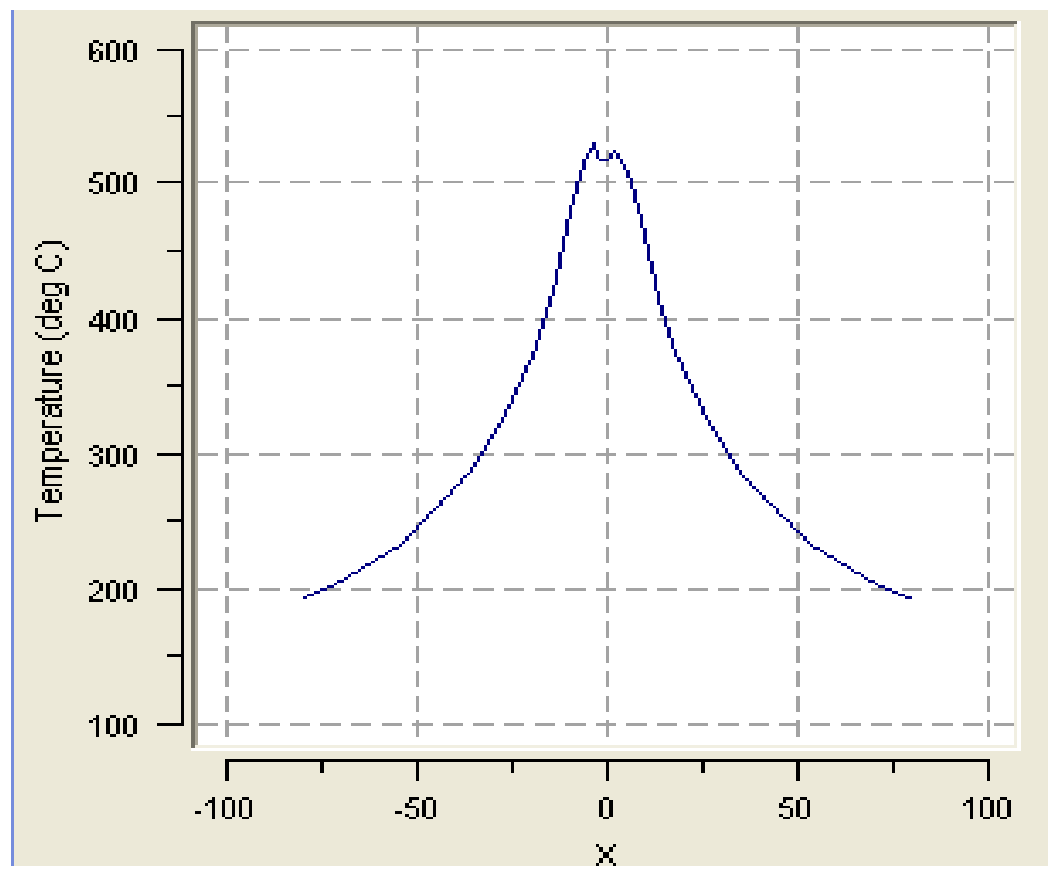

Figure 6b: RS $=1000 \mathrm{rpm}, \mathrm{WS}=40 \mathrm{~mm} / \mathrm{min},(\mathrm{Pin}=\mathrm{TSCP})$ Max. Temp $=5360 \mathrm{o} ; \mathrm{TS}=57.40 \mathrm{Mpa}$ 


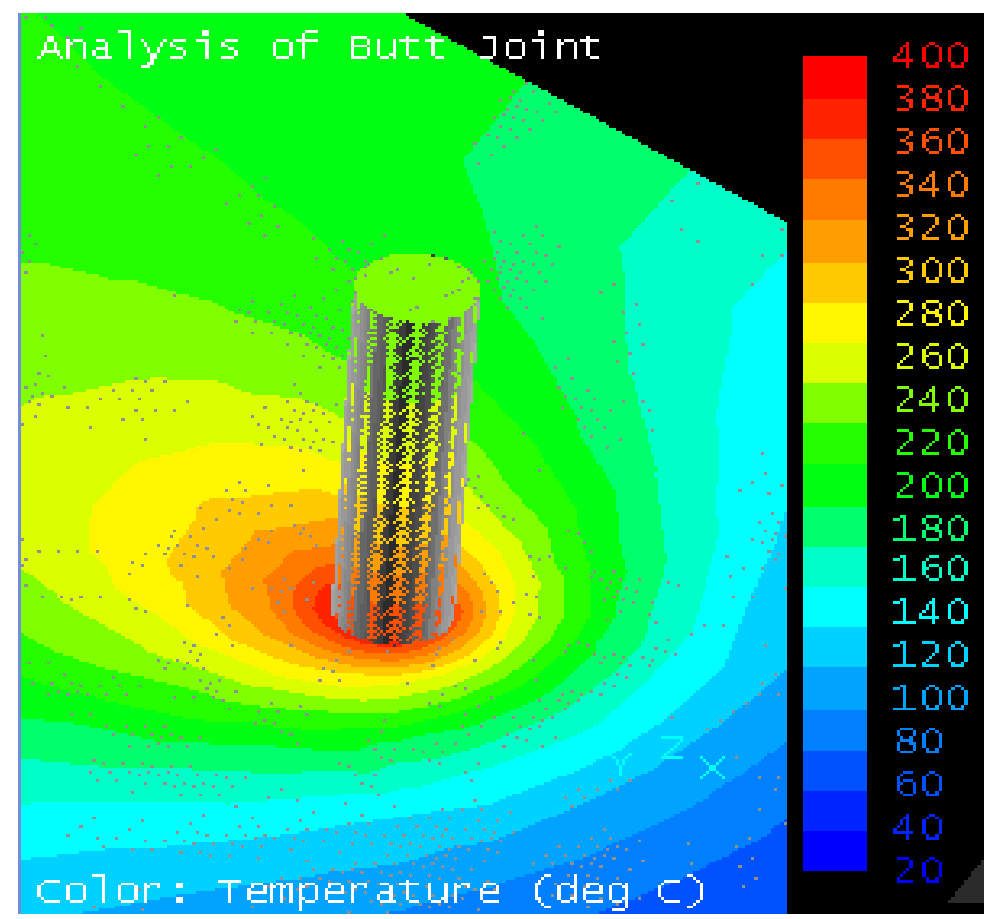

Figure 7a: $\mathrm{RS}=710 \mathrm{rpm}, \mathrm{WS}=56 \mathrm{~mm} / \mathrm{min},(\mathrm{Pin}=\mathrm{SCP})$

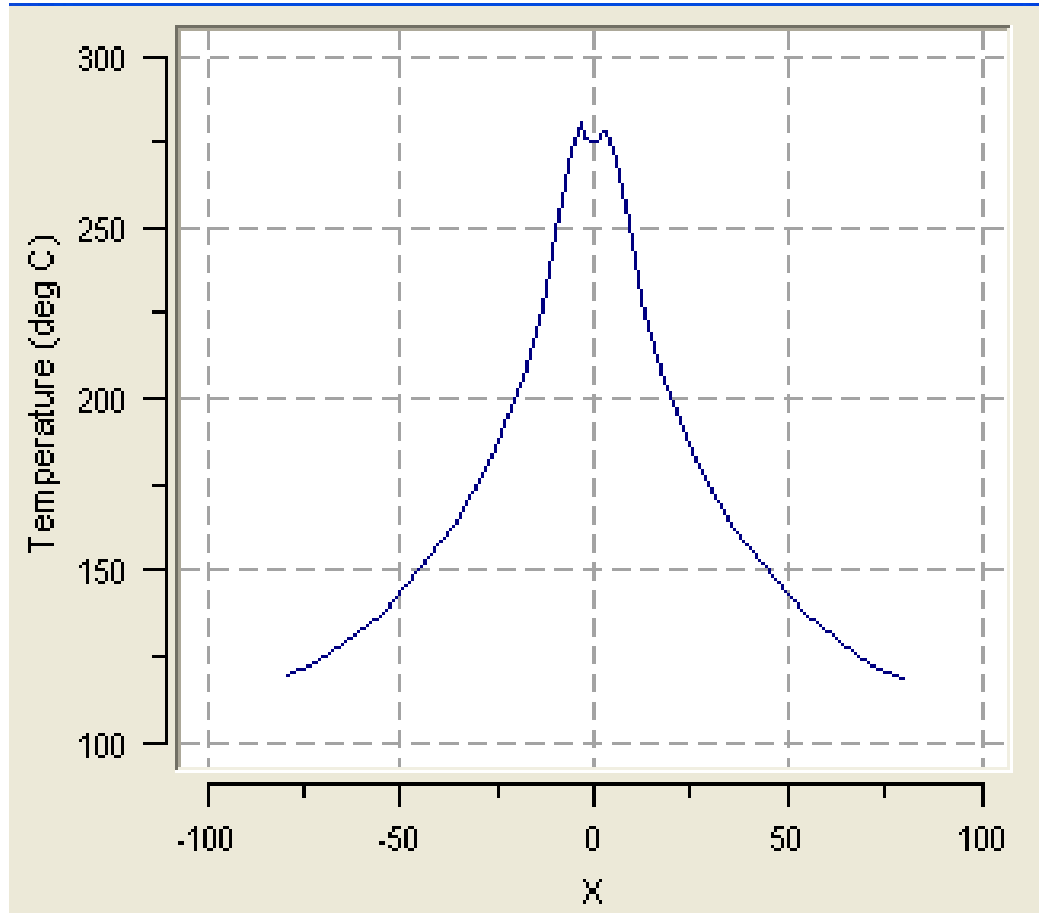

Figure 7b: RS $=710 \mathrm{rpm}, \mathrm{WS}=56 \mathrm{~mm} / \mathrm{min},(\mathrm{Pin}=\mathrm{SCP})$ Max. Temp $=285 \mathrm{oC} ; \mathrm{TS}=8.91 \mathrm{MPa}$ 


\section{Conclusion}

In this investigation, observations were made for the tensile strength of weld zone, and optical microscopy of cross section of weld pools to select proper tool pin profile, proper welding speed and tool rotational speed. The peak temperatures for best tensile strength $\&$ the lowest tensile strength were found by simulation for experiments no. 1, 2, 5 and 7 for predicting and correlating the best welding parameters with tensile strengths. From this investigation \& simulations, the following conclusions are derived:

(1) Heat generated during experiment no. 1 may produce a peak temperature of $490 \mathrm{oC}$ at the rotational speed of $710 \mathrm{rpm}$ and welding speed of $28 \mathrm{~mm} / \mathrm{min}$ using threaded straight cylindrical pin (TSCP) profile. During this, tensile strength obtained is the maximum one. Increase in rotational speed \& welding speed produces a higher temperature, but higher welding speed results in poor flow of metals from advancing side to retreating side and so, lower weld strength at RS $=1000 \mathrm{rpm} \&$ $\mathrm{WS}=40 \mathrm{~mm} / \mathrm{min}($ Fig $-6(a) \& 6(b))$ is found as $57.40 \mathrm{MPa}$.

(2) Tapper cylindrical pin (TCP) profile of the tool may produce a lower peak temperature of $393 \mathrm{oC}$ when $\mathrm{RS}=1000 \mathrm{rpm} \& \mathrm{WS}=56 \mathrm{~mm} / \mathrm{min}$. The reason being taper pin profile and less time for flow of metal as the welding progresses. A lower tensile strength of 11.17 MPa is observed.

(3) During experiment no. 7 using straight cylindrical pin (SCP) profiled tool with $\mathrm{RS}=710 \mathrm{rpm}$ and $\mathrm{WS}=56 \mathrm{~mm} / \mathrm{min}$, it may produce a peak temperature of $285 \mathrm{oC}$ only. This would have resulted in a tensile strength of only $8.91 \mathrm{MPa}$, indicating effect of pin profile as well as welding speed. A somewhat small defect at top surface of weld zone is also observed (Fig -3$)$.

(4) Based on this investigation \& simulations, it can be further concluded that besides the rotational speed and welding speed during FSW of any alloy or metal, tensile strength obtained for the weld joint also depends upon the tool pin profiles. Similarly, a higher peak temperature achieved by FSW does not always produce a high strength but it is also dictated by tool pin profiles.

(5) For a selected plate and tool materials during this investigation, best welding parameters suggested are $710 \mathrm{rpm}$ and $28 \mathrm{~mm} / \mathrm{min}$ to obtain the best strength value without welding defects.

\section{References}

[1] W. M. Thomas, E. D. Nicholas, J. C. Needham, M, G. Murch, P. Templesmith, and C. J. Dawes, G.B. Patent 9125978.8, Dec 1991.

[2] S. Ugender, A. Kumar, A. Somi Reddy, "Experimental investigation of tool geometry on mechanical properties of friction stir welding of AA 2014 Aluminium Alloy”, Procedia Materials Science, vol5, page $824-831,2014$.

[3] K.D.Bhatt, Bindu Pillai, \& Dr. A.M. Trivedi, "Effect of Size of Tool on Peak Temperature \& Viscosity during Friction Stir Welding of AA6061-T6 Aluminium Alloy Using Hyperworks", International Journal of Innovative Research in Science, Engineering and Technology Vol. 2, Issue 4, April 2013.

[4] K.D.Bhatt, Bindu Pillai, "Simulation of Peak Temperature \& Flow Stresses during Friction Stir Welding of AA7050-T7451 Aluminium Alloy Using Hyperworks", International Journal of Emerging Technology and Advanced Engineering, Volume 2, Issue 5, May 2012. 
[5] S. Ramesh Babu, V.S.SenthilKumar, G,Madhusudhan Reddy, "Microstructural changes and mechanical properties of friction stir processes extruded AZ31B alloy", international conference on modelling optimization and computing, vol 32, page 2956-2966, 2012.

[6] K Panneerselvam, Lenin K, "Investigation on effect of tool forces and joint defects during FSW polypropylene plate", international conference on modeling optimization and computing, vol 38, page 3927-3940, 2012.

[7] F.Y. Zheng, Y.J. Wu, L.M. Peng, X.W. Li, P.H. Fu, W.J. Ding, "Microstructures and mechanical properties of friction stir processed Mge2.0Nde0.3Zne1.0Zr magnesium alloy", journal of magnesium and alloys, vol 1, page 122-127, 2013.

[8] Chaitanya Sharma, Dheerendra Kumar Dwivedi, Pradeep Kumar, "Heterogeneity of microstructure and mechanical properties of friction stir welded joints of Al-Zn-Mg alloy AA7039", international conference on design and manufacturing, vol 64, page 1384-1394, 2013.

[9] Mohsen Bahrami, Mohammad KazemBesharatiGivi, Kamran Dehghani, Nader Parvin, "On the role of pin geometry in microstructure and mechanical properties of AA7075/SiC nano-composite fabricated by friction stir welding technique", Materials and Design, vol 53, page 519-527, 2014.

[10] EmadSalari, Mohammad Jahazi, AlirezaKhodabandeh, HadiGhasemi-Nanesa, "Influence of tool geometry and rotational speed on mechanical properties and defect formation in friction stir lap welded 5456 aluminum alloy sheets”, Materials and Design. vol 58, page 381-389, 2014.

[11] K. Elangovan, V. Balasubramanianb, "Influences of tool pin profile and welding speed on the formation of friction stir processing zone in AA2219 aluminium alloy", Materials and Design, vol 58, page 381-389, 2014.

[12] Mahoney M.W., Rhodes C.G., Flintoff J.G., Spurling R.A. and Bingel W.H. Metall. Mater. Trans. A29 (1998) 1955.

[13] Sato Y.S., Kokawa H., Enmoto M. and Jogan S. Metall. Mater. Trans. A,vol. 30, pp 2429, 1999.

[14] Tang W., Guo X., McClure J.C. and Murr L.E. J. Mater. Process. Manufact. Sci., vol. 7, pp 163, 1998.

[15] Kwon Y.J., Saito N. and Shigematsu I. J. Mater. Sci. Lett., Vol. 21, pp 1473, 2002.

[16] Rhodes C.G., Mahoney M.W., Bingel W.H., Spurling R.A. and Bampton C.C. Scripta Mater, Vol. 36, pp 69, 1997.

[17] Liu G., Murr L.E., Niou C.S., McClure J.C. and Vega F.R. Scripta Mater, vol. 37, pp 355, 1997.

[18] Mishra R.S. and Ma Z.Y. 2005. Friction stir welding and Processing, Reports: A Review Journal. doi: 10.1016/j.mser.2005.07.001.

[19] Vinayak Malik, Sanjeev N K, H. Suresh Hebbar, Satish V. Kailas, "Investigations on the Effect of Various Tool Pin Profiles in Friction Stir Welding Using Finite Element Simulations", Procedia Engineering, vol. 97, page1060 - 1068, 2014.

[20] Mr. P H Shah, Dr. Vishvesh Badheka, "An experimental investigation of temperature distribution and joint properties of Al 7075 T651 friction stir welded aluminium alloys", Procedia Technology, vol. 23, pp 543-550, 2016.

[21] Sahin Suenger, Michael Kreissle, Markus Kahnert, Michael F. Zaeh,” Influence of Process Temperature on Hardness of Friction Stir Welded High Strength Aluminum Alloys for Aerospace Applications", Procedia CIRP, vol. 24, pp 120-124, 2014.

[22] B. Ratna Sunil, G. Pradeep Kumar Reddy, A.S.N. Mounika, P. Navya Sree, P. Rama Pinneswari, I. Ambica, R. Ajay Babu, P. Amarnadh," Joining of AZ31 and AZ91 Mg alloys by friction stir welding”, Journal of Magnesium and Alloys, vol. 3, pp 330-334, 2015. 
[23] P. Rama Pinneswari, I. Ambica, R. Ajay Babu, P. Amarnadh, "Joining of AZ31 and AZ91 Mg alloys by friction stir welding”, Journal of Magnesium and Alloys, vol 3, page 330-334, 2015.

[24] Ugender Singarapu, Kumar Adepu, Somi Reddy Arumalle, "Influence of tool material and rotational speed on mechanical properties of friction stir welded AZ31B magnesium alloy", Journal of Magnesium and Alloys, vol 3, page 335-344, 2015.

[25] Nikul Patel, K.D.Bhatt, Vishal Mehta, "Influence of Tool Pin Profile and Welding Parameter on Tensile Strength of Magnesium Alloy AZ91 during FSW", Procedia Technology, vol. 23, pp 558 - 565, 2016. 